\title{
Editorial
}

International Archives of
Allergy
Immunology

\section{Ready for a Milk Shake?}

\author{
Heidrun Hochwallner \\ Division of Immunopathology, Department of Pathophysiology and Allergy Research, Center for \\ Pathophysiology, Infectiology and Immunology, Medical University of Vienna, Vienna, Austria
}

Cow's milk allergy strongly affects the quality of life of patients and their families and the only specific and causative treatment besides avoidance is specific immunotherapy (SIT). However, SIT must be performed over a long period, is often accompanied by severe side effects and its success rate is affected by a variety of factors, among them the patient's compliance. Quite often, patients treated with SIT are not properly selected and monitored during therapy. The monitoring of the effects of SIT, especially the immunological parameters, may provide useful information regarding the continuation or discontinuation of treatment. Diagnostic surrogate markers for the prediction of the outcome of immunotherapy are still missing and badly needed.

Several rather cumbersome approaches towards suitable markers have been pursued. Complex gene expression profiles, in the case of venom immunotherapy [1], and impaired pulmonary function in conjunction with age, in the case of house dust mite immunotherapy, have been used as indicators for a lower success rate [2]. Other markers include the reduction of allergen-specific $\mathrm{T}$ cell proliferation, shown in sublingual immunotherapy studies involving birch pollen [3] and house dust mite [4]. Ideally, the use of biomarkers should already be possible during treatment, in order to predict the outcome [5].

The article by Savilahti et al. [6] in International Archives of Allergy and Immunology is a rather conservative but robust approach towards the identification of markers that enable the prediction of the outcome of oral immunotherapy for cow's milk allergy. By means of ELISA, the authors determined specific IgE, IgA, IgG subclass levels against cow's milk extract, natural single cow's milk allergens and the egg allergen ovalbumin in 40 children with cow's milk allergy before and after immunotherapy. Seventy-six children with no history of cow's milk allergy and 56 children who recovered spontaneously from their milk allergy served as a reference. The researchers found differences in antibody levels between groups and concluded that high levels of cow's milk-specific IgE, IgA and IgG before immunotherapy may be good indicators for the failure of tolerance, similar to constant IgA and $\operatorname{IgE}$ levels during immunotherapy.

The course of IgE levels during therapy has been described differently in different articles; some studies observed that levels of IgE remained constant whereas others noticed a decrease or increase. A clearer picture is reported for allergen-specific $\mathrm{IgG}_{4}$ levels: low cow's milk-specific $\operatorname{IgG}_{4}$ levels indicate a persistent allergy and also a negative outcome of oral immunotherapy. The role of IgA during tolerance development has been investigated less and needs to be studied in more detail.

The importance of Savilahti et al.'s [6] article is the topic of the study, the search for objective markers which can be easily evaluated during the course of an immunotherapy and help to predict the outcome. Allergen-specif-

\section{KARGER}

E-Mail karger@karger.com

www.karger.com/iaa (c) 2014 S. Karger AG, Basel

$1018-2438 / 14 / 1643-0167 \$ 39.50 / 0$
Correspondence to: Dr. Heidrun Hochwallner

Division of Immunopathology, Department of Pathophysiology and Allergy Research Medical University of Vienna, Waehringer Guertel 18-20 AT-1090 Vienna (Austria)

E-Mail heidrun.hochwallner@meduniwien.ac.at 
ic IgA levels were also measured and taken into account for the first time. The authors suggest that increases in levels of cow's milk-specific $\operatorname{IgA}, \operatorname{IgG}, \operatorname{IgG}_{1}$ and $\operatorname{IgG}_{4}$ accompanied by a decrease in allergen-specific IgE are associated with successful treatment, but that there is no improvement when there is no decrease of allergen-specific IgE. It is clear that objective parameters such as allergen-specific antibody levels would constitute simple and practical parameters for assessing the effects of SIT, as opposed to the flaws that come with subjective assessments like reports by patients [7].

This study has its weak points, however. The samples size of the group that failed to achieve tolerance was small, therefore the statistical evaluation must be regarded with caution. The levels of IgG and IgA antibodies might depend on the age of the patients; children between 6 and 17 years of age were tested here, but these levels might be completely different in adults. Some studies support the measurement of allergen-specific IgG and IgA levels [8], but more recent studies recommend the use of bioassays to determine not only the levels of the induced antibodies but also their functional inhibitory capacity [5].

Microarrays, containing all relevant allergens in their pure form, may be helpful tools for the monitoring of blocking antibody levels during immunotherapy [9]. Up to now, microarrays have been used for the diagnosis of allergy and for the determination of the symptom-eliciting allergens. A recent study suggested that IgE measurements with microarrays may be suitable as biomarkers because measurements on the chip are performed under conditions with low amounts of allergens and so the blocking activity of IgG can be visualized in the form of a reduction of the IgE signal. Clinical studies are necessary to confirm this.

\section{References}

-1 Niedoszytko M, Bruinenberg M, de Monchy J, Wijmenga C, Platteel M, Jassem E, Oude Elberink JN: Gene expression analysis in predicting the effectiveness of insect venom immunotherapy. J Allergy Clin Immunol 2010; 125:1092-1097.

-2 Bousquet J, Hejjaoui A, Clauzel AM, Guerin B, Dhivert H, Skassa-Brociek W, Michel FB: Specific immunotherapy with a standardized Dermatophagoides pteronyssinus extract. II. Prediction of efficacy of immunotherapy. J Allergy Clin Immunol 1988;82:971-977.

$>3$ Bohle B, Kinaciyan T, Gerstmayr M, Radakovics A, Jahn-Schmid B, Ebner C: Sublingual immunotherapy induces IL-10-producing T regulatory cells, allergen-specific $\mathrm{T}$ cell tolerance, and immune deviation. J Allergy Clin Immunol 2007;120:707-713.
4 O'Hehir RE, Gardner LM, de Leon MP, Hales BJ, Biondo M, Douglass JA, Rolland JM, Sandrini A: House dust mite sublingual immunotherapy: the role for transforming growth factor beta and functional regulatory T cells. Am J Respir Crit Care Med 2009;180:936-947.

5 Till S: Mechanisms of immunotherapy and surrogate markers. Allergy 2011;66(suppl 95):25-27.

6 Savilahti EM, Kuitunen M, Savilahti E, Mäkelä MJ: Specific antibodies in oral immunotherapy for cow's milk allergy: kinetics and prediction of clinical outcome. Int Arch Allergy Immunol 2014;164:32-39.

7 Cox L, Nelson H, Lockey R, Calabria C, Chacko T, Finegold I, Nelson M, Weber R, Bernstein DI, Blessing-Moore J, Khan DA, Lang DM, Nicklas RA, Oppenheimer J, Portnoy JM, Randolph C, Schuller DE, Spector SL, Tilles S, Wallace D: Allergen immunotherapy: a practice parameter third update. J Allergy Clin Immunol 2011;127:S1-S55.
8 Francis JN, James LK, Paraskevopoulos G, Wong C, Calderon MA, Durham SR, Till SJ: Grass pollen immunotherapy: IL-10 induction and suppression of late responses precedes IgG4 inhibitory antibody activity. J Allergy Clin Immunol 2008;121:1120-1125.

$>9$ Lupinek C, Wollmann E, Baar A, Banerjee S, Breiteneder $\mathrm{H}$, Broecker BM, Bublin M, Curin M, Flicker S, Garmatiuk T, Hochwallner H, Mittermann I, Pahr S, Resch Y, Roux KH, Srinivasan B, Stentzel S, Vrtala S, Willison LN, Wickman M, Lodrup-Carlsen KC, Anto JM, Bousquet J, Bachert C, Ebner D, Schlederer T, Harwanegg C, Valenta R: Advances in allergen-microarray technology for diagnosis and monitoring of allergy: the MeDALL allergen-chip. Methods 2014;66: 106-119. 